\title{
A Novel Concentric Annular-Ring Slot Dual-Band Circularly Polarized Microstrip Antenna
}

\author{
Yong Cheng $\mathbb{D}$ and Hui Liu \\ College of Electronic and Optical Engineering, Nanjing University of Posts and Telecommunications, Nanjing, Jiangsu 210003, China \\ Correspondence should be addressed to Yong Cheng; chengy@njupt.edu.cn
}

Received 24 May 2018; Revised 24 September 2018; Accepted 11 October 2018; Published 13 December 2018

Academic Editor: N. Nasimuddin

Copyright (c) 2018 Yong Cheng and Hui Liu. This is an open access article distributed under the Creative Commons Attribution License, which permits unrestricted use, distribution, and reproduction in any medium, provided the original work is properly cited.

A simple structure concentric annular-ring slot dual-band circularly polarized (CP) microstrip antenna operating at ISM band $(2.45 \mathrm{GHz})$ and $5 \mathrm{G}$ band $(3.5 \mathrm{GHz})$ is proposed in this paper. The antenna achieves dual-band operation by digging two concentric annular-ring slots on the ground. And on the angular positions with 45 degrees inclined of each annular slot, two bent structures are loaded to generate circularly polarized radiation. The radiation of this antenna is bidirectional, and the directions of rotation are opposite. The measured results of the annular-ring slot microstrip antenna show good performance of dual-band circularly polarized characteristics.

\section{Introduction}

Compared to conventional antennas, the microstrip antenna get easier implementation of dual-band and circular polarization. There are many ways to realize circular polarization in microstrip antenna. Divided by number of feed points, there are two types: single feed and dual feed. Circularly polarized microstrip antenna with single feed is the simplest microstrip antenna. By introducing some kind of asymmetric degeneracy separation unit in the structure, the two resonant modes can be excited with two orthogonal linear polarizations with nearly equal amplitude and $90^{\circ}$ phase difference to achieve CP characteristics [1]. Numerous studies for antennas of single-feed circular polarization can be found in the literature [2-7]. Another method is to excite two resonant modes to achieve circular polarization by dual feed. In contrast to the single-feed circularly polarized antenna, it is necessary to add a feed network including a phase shift network and a power division network [8] to ensure that these two modes are equal in amplitude and have a phase difference of $90^{\circ}$. That also makes the structure of such an antenna more complex than a single-feed circularly polarized antenna.

In this paper, a novel concentric annular-ring slot dualband CP microstrip antenna that operates at ISM band
$(2.45 \mathrm{GHz})$ and $5 \mathrm{G}$ band $(3.5 \mathrm{GHz})$ is proposed and investigated. The antenna is a kind of single-layer slot antenna. There are two concentric ring slots of different size on the ground to generate dual-band radiation. The two symmetrical corners of the ring slots are added with two bent structures to achieve circular polarization. On the other side of the antenna, microstrip lines are used to excite the annularring slots with two bent structures. The feed line is located below the central axis of the annular-ring slot and finally realizes bidirectional circularly polarized radiation.

\section{Antenna Design Principle}

The structure diagram of both positive and negative side of the proposed dual-band LHCP annular-ring slot antenna is showed in Figure 1. It is printed on a $60 \mathrm{~mm} \times 60 \mathrm{~mm}$ FR4 dielectric board with relative dielectric constant $\varepsilon_{\mathrm{r}}=4.4$, loss $\operatorname{tangent} \tan \delta=0.02$, and thickness $h=1.6 \mathrm{~mm}$. One side of the dielectric plate is coated with copper as the ground, and two concentric ring slots are digged on the ground to determine the resonant frequencies of the antenna. The simulated surface current distributions of the antenna operating at $2.45 \mathrm{GHz}$ and $3.5 \mathrm{GHz}$ are depicted in Figure 2. Dense current distributions are mainly on the outer ring at $2.45 \mathrm{GHz}$ and on the inner ring at $3.5 \mathrm{GHz}$. They all have a 


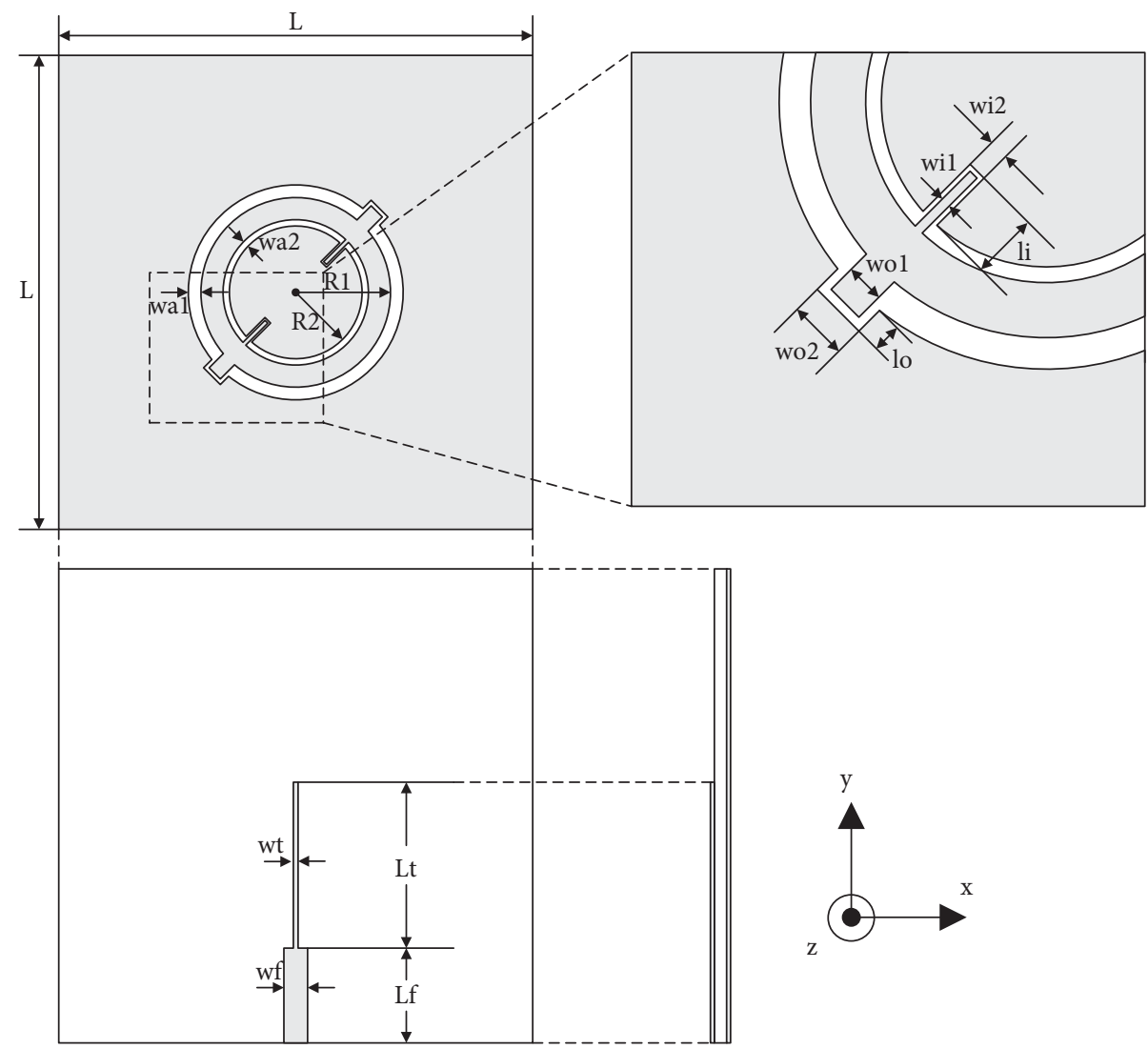

FIgURE 1: Both positive and negative side of the proposed dual-band LHCP annular-ring slot antenna.

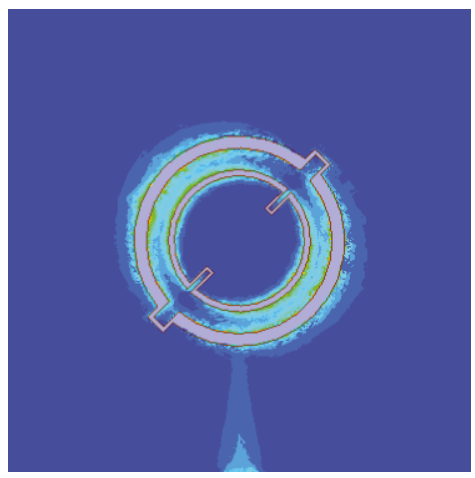

(a)
Jsurf (A_per_m)

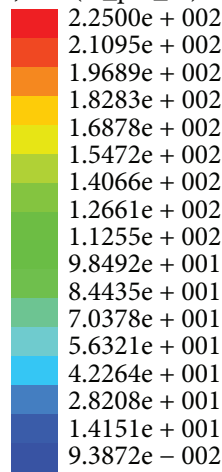

$9.3872 \mathrm{e}-002$

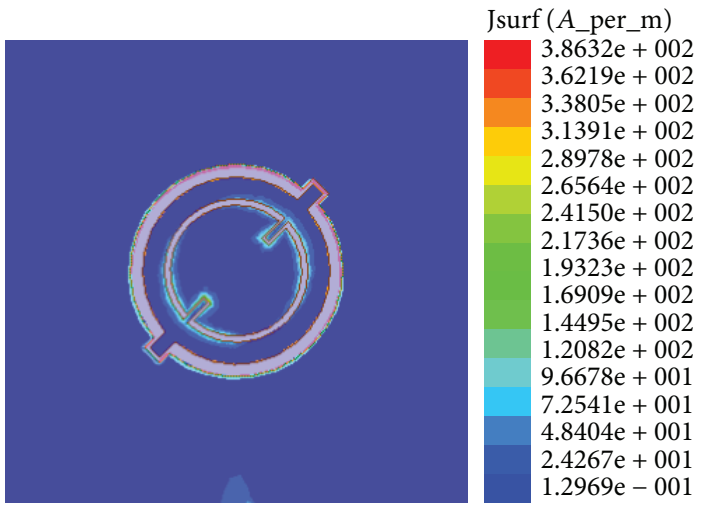

(b)

FIgURE 2: The simulated surface current distributions of the antenna operating at (a) $2.45 \mathrm{GHz}$ and (b) $3.5 \mathrm{GHz}$.

periodic distribution, which is due to the circumferential length of the annular-ring slot being equal to the wavelength of the medium. In the current distribution diagram, it can be seen that the two annular-ring slots, respectively, control the generation of two resonant frequency points.

Figures 3 and 4 show the current distribution along the surface of the annular-ring slot antenna at $2.45 \mathrm{GHz}$ and $3.5 \mathrm{GHz}$ with different phase angles. It can be seen that the radiant current vector is mainly clockwise as the phase changes. Therefore, antenna exhibits LHCP radiation in the positive direction of the $Z$-axis and $\mathrm{RHCP}$ radiation in the negative direction of the $Z$-axis.

The perturbation of the bent structure is, respectively, introduced at two diagonal positions of an oblique 45 degrees of each annular slot, so that the resonant modes of the two frequency bands are degenerately separated to form circularly polarized radiation. The bent structure of the inner ring is bent to the center of the ring, and the outer ring turns to the opposite direction away from the ring center. This structure not only can facilitate the nesting design of the two rings in 


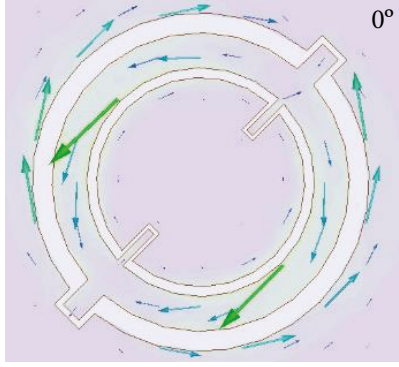

(a)

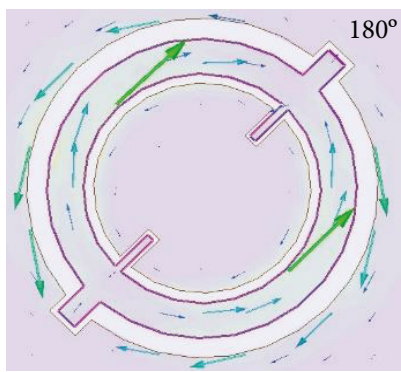

(c)

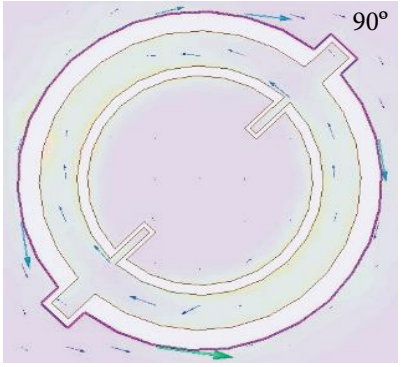

(b)

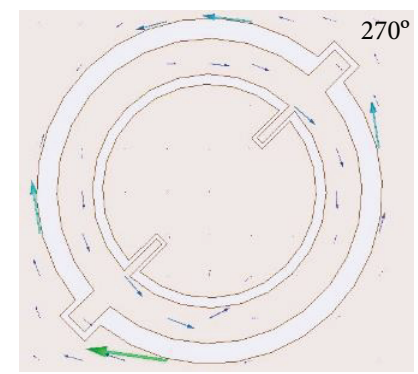

(d)

Figure 3: The current distribution for different phase angles at $2.45 \mathrm{GHz}$.

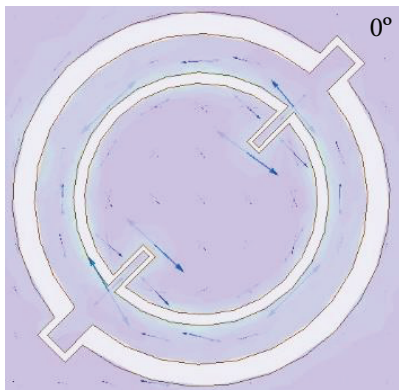

(a)

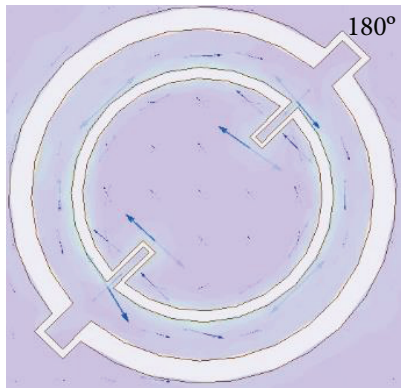

(c)

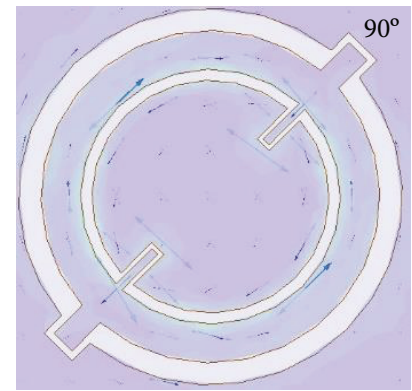

(b)

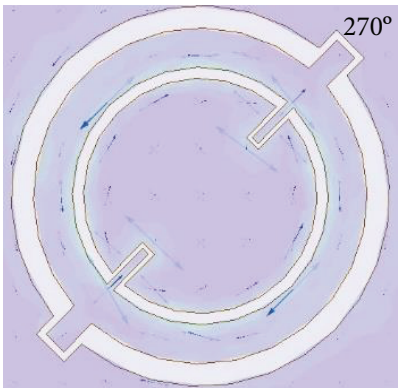

(d)

FIgURE 4: The current distribution for different phase angles at 3.5 GHz.

geometry but also can minimize the affect between the two rings as much as possible. Thus, there is more room for adjusting the size of the annular-ring slot and the bent structure in the design. The other side of the dielectric plate is a microstrip, feeding the annular-ring slot on the ground, and the upper part of the feeder line is a quarterwavelength impedance matching line to adjust the impedance of the antenna.
The value of each parameter of the antenna needs to be finely adjusted and optimized. The values of the radius R1 and $\mathrm{R} 2$ of the two rings, respectively, determine the resonant frequencies of the antenna, and the width of the annular-ring slot has a great influence on the input impedance of the ring microstrip. wi1, wi2, li and wo1, wo2, lo, respectively, control the size of the bending structure on the inner and outer rings. As a key structure for generating circular polarization, the 
bent structure has a great influence on the frequency points and $3 \mathrm{~dB}$ bandwidth of the circular polarization axis ratio parameter. The impact of these parameters on antenna performance is introduced as below. Table 1 shows the values of the parameters in the final design of the antenna.

2.1. Ring Resonant Structure Design. The resonant frequency $(2.45 \mathrm{GHz})$ of the lower band depends mainly on the outer annular ring, while the upper one $(3.5 \mathrm{GHz})$ depends on the inner annular ring. Therefore, the circumferential length of the annular-ring slot needs to satisfy the dielectric wavelength at the corresponding frequency point, which is

$$
\begin{aligned}
& \mathrm{R}_{1}+\frac{\mathrm{wa} 1}{2}=\lambda_{1} \\
& \mathrm{R}_{2}+\frac{\mathrm{wa} 2}{2}=\lambda_{2} .
\end{aligned}
$$

The width of the slot has a great influence on the impedance matching characteristics of the antenna. For example, when we change the width wal of the outer ring slot, the input-scattering parameter of the antenna is shown as in Figure 5. The figure notes that when wal $=2.1 \mathrm{~mm}$, the performance of the antenna's input-scattering parameter at the low frequency band deteriorates as a whole, only $-13 \mathrm{~dB}$ at $2.45 \mathrm{GHz}$. The lowest point of $\mathrm{S}_{11}$ curve shifts to lower frequency band. $S_{11}$ curve is split into two bands at the high frequency band, and performance is not ideal. When wal $=1.1 \mathrm{~mm}, \mathrm{~S}_{11}$ curve is split into two peaks at the lower frequency band. Although the bandwidth is broadened, $S_{11}$ is poor in the band center compared to wa $1=1.6 \mathrm{~mm}$. The higher frequency band has less influence and only slightly shifted toward higher frequencies. Therefore, the width of the outer ring slot is $1.6 \mathrm{~mm}$.

2.2. Bent Perturbation Structure Design. As a key structure for forming circularly polarized radiation, the size of the bent structure has a great influence on the axial ratio of the circular polarization performance of the antenna. When selecting, it is necessary to comprehensively consider the effects of various parameters such as length, width, and slot width.

Still taking the outer ring as an example, the outer ring bent structure controls the axial ratio of $2.45 \mathrm{GHz}$ frequency point at the lower frequency band. When the outward bent length lo takes different sizes, the axis ratio of the antenna at the lower frequency band is shown in Figure 6. It can be seen from the figure that when $10=2.7 \mathrm{~mm}, 1.7 \mathrm{~mm}$, and $0.7 \mathrm{~mm}$, the minimum axial ratio is $2.5 \mathrm{~dB}, 1 \mathrm{~dB}$, and $1.1 \mathrm{~dB}$ at $2.3 \mathrm{GHz}, 2.44 \mathrm{GHz}$, and $2.54 \mathrm{GHz}$, respectively. The picture clearly demonstrates that with the increase of the length of the outward bent, the frequency point of the minimum axis ratio moves toward the lower frequency band. After debugging, the length of the outer ring bent is $l o=1.7 \mathrm{~mm}$.

2.3. Microstrip Feed Structure Design. The antenna is fed by a microstrip side feed. In the design, it is necessary to adjust the height position Lf and the width wt of the feeder to best match the antenna impedance at the two frequency bands.
TABLE 1: Value of each parameter.

\begin{tabular}{lccccccc}
\hline Parameter & R1 & R2 & wa1 & wa2 & wi1 & wi2 & wo1 \\
Value $(\mathrm{mm})$ & 12 & 8.4 & 1.6 & 0.8 & 0.6 & 1.2 & 1.8 \\
\hline Parameter & wo2 & li & lo & wt & wf & Lt & Lf \\
Value $(\mathrm{mm})$ & 2.8 & 3.1 & 1.7 & 0.6 & 3 & 21 & 6 \\
\hline
\end{tabular}

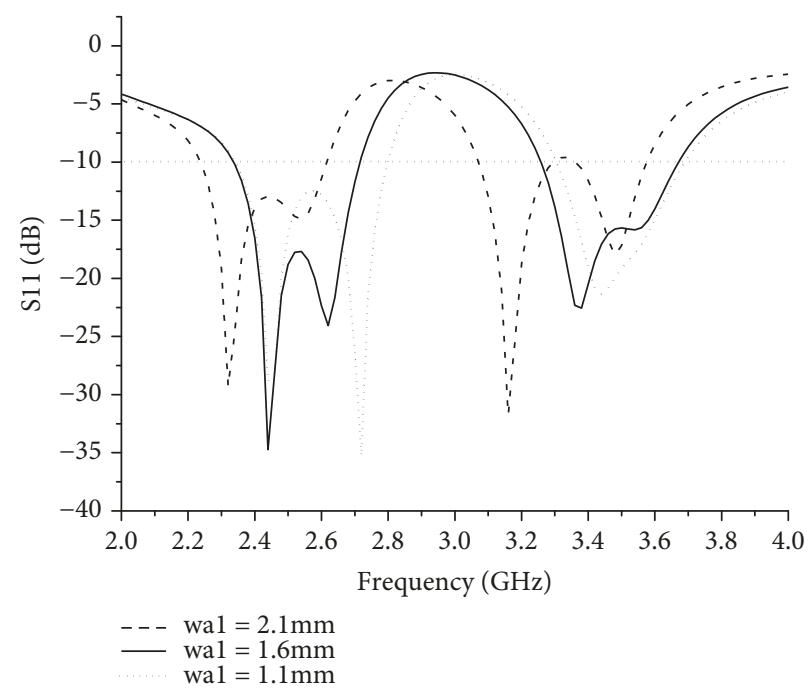

FIgURE 5: Simulated $S_{11}$ with different values of wa1.

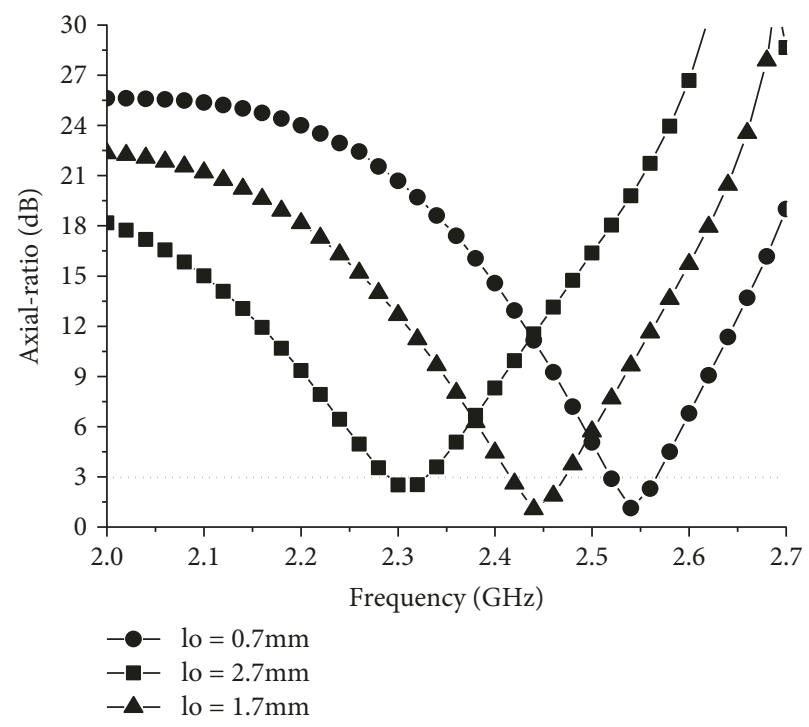

Figure 6: Simulated axial ratio with different values of lo.

Figure 7 shows the comparison of the antenna $S_{11}$ curve when Lf is taken in different sizes. The figure shows that when $\mathrm{Lf}=5 \mathrm{~mm}$, the performance of the antenna in both frequency bands is seriously deteriorated, resulting in $S_{11}$ is $-12.8 \mathrm{~dB}$ at $2.45 \mathrm{GHz}$ and $-10.5 \mathrm{~dB}$ at $3.5 \mathrm{GHz}$, which is just enough to meet less than $-10 \mathrm{~dB}$ compared to the other two curves, and the frequency band is severely narrowed at $3.5 \mathrm{GHz}$. When $\mathrm{Lf}=7 \mathrm{~mm}$, they all shift slightly to higher 


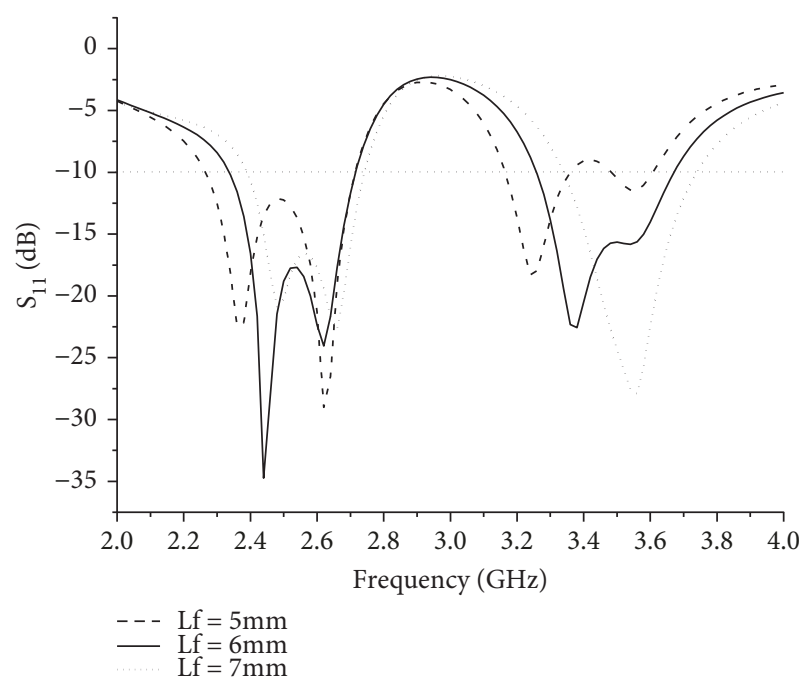

Figure 7: Simulated $S_{11}$ with different values of Lf.

frequencies, although the two frequency bands $S_{11}$ perform well. By comprehensive comparison, the band position and performance of $S_{11}$ are better than the other two cases when Lf $=6 \mathrm{~mm}$, so the height position Lf of the quarterwavelength matching line is chosen to be $6 \mathrm{~mm}$.

\section{Results}

According to the design analysis and optimization results in Section 2, the physical objects were fabricated and measured with a vector network analyzer and a near-field test system. Figure 8 shows the fabricated dual-band $\mathrm{CP}$ antenna.

Figure 9 shows the simulated and measured $S_{11}$ of the proposed antenna. From the comparison in the figure, the measurement curve of $S_{11}$ roughly coincides with the simulation. The measured $-10 \mathrm{~dB}$ impedance bandwidths are about $14 \%$ ranging from $2.38 \mathrm{GHz}$ to $2.74 \mathrm{GHz}$ for the lower band and $10 \%$ ranging from $3.31 \mathrm{GHz}$ to $3.66 \mathrm{GHz}$ for the upper band. The $\mathrm{S}_{11}$ is $-24.7 \mathrm{~dB}$ at $2.45 \mathrm{GHz}$ and $-17 \mathrm{~dB}$ at $3.5 \mathrm{GHz}$. Both bands are slightly offset to the higher frequencies compared to the simulation results, but still meet design specifications. The antenna exhibits good dual-band operation characteristics.

Figure 10 plots the simulated and measured axis ratio varied with frequency in the positive $Z$-axis direction of the antenna and shows very good agreement at low frequency band. The measured $\mathrm{CP}$ bandwidth defined by $-3 \mathrm{~dB}$ axial ratio (AR) are $30 \mathrm{MHz}(2.43 \mathrm{GHz}-2.46 \mathrm{GHz})$ for the lower band and $0.7 \mathrm{~dB}$ at $2.45 \mathrm{GHz}$. The measured $-3 \mathrm{~dB}$ AR bandwidth for the upper band is $40 \mathrm{MHz}(3.47 \mathrm{GHz}-3.51 \mathrm{GHz})$ and $0.78 \mathrm{~dB}$ at $3.5 \mathrm{GHz}$. Comparing the measured $\mathrm{S}_{11}$ graph of Figure 7, it can be seen that those bands are completely covered by the two impedance bandwidths of the antenna; thus, those bands are the frequency bands where the antenna can achieve circular polarization.

Figure 11(a) represents the measured gain of the antenna varied with the frequency. The graph shows that the curve exhibits a bimodal characteristic with a high gain in both operating frequency bands, which is basically consistent with

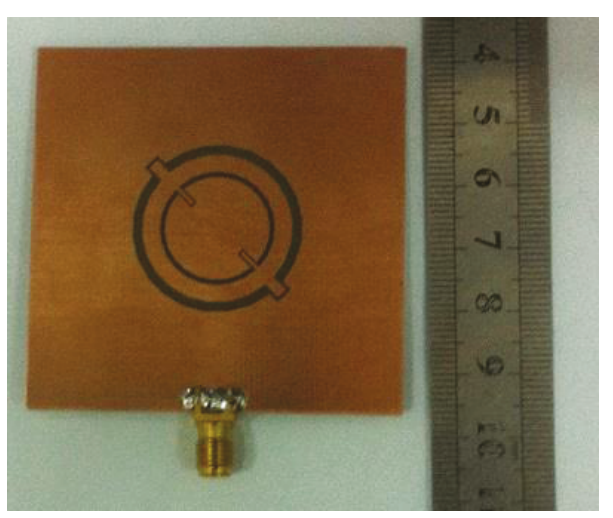

FIgURE 8: Photograph of the fabricated dual-band CP antenna.

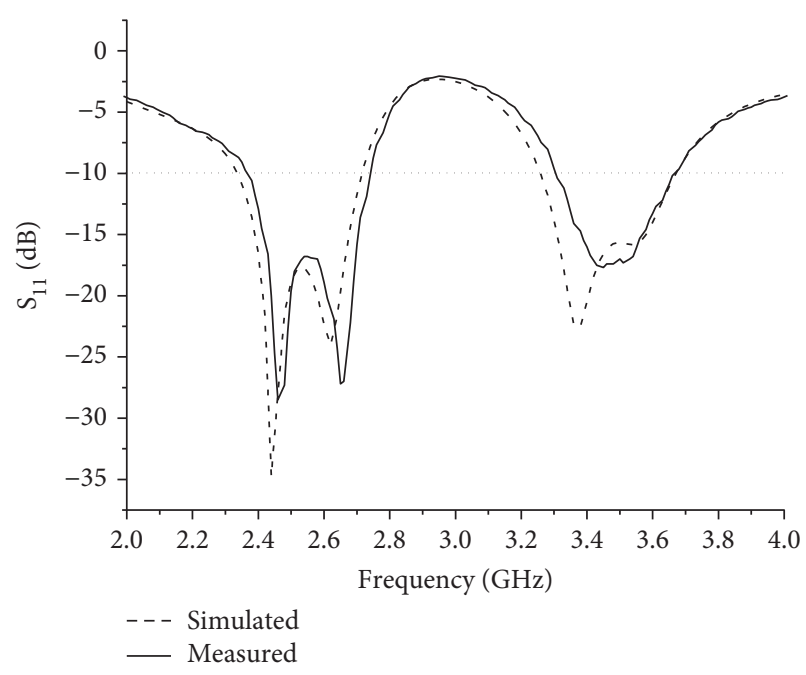

Figure 9: Simulated and measured $S_{11}$ of antenna.

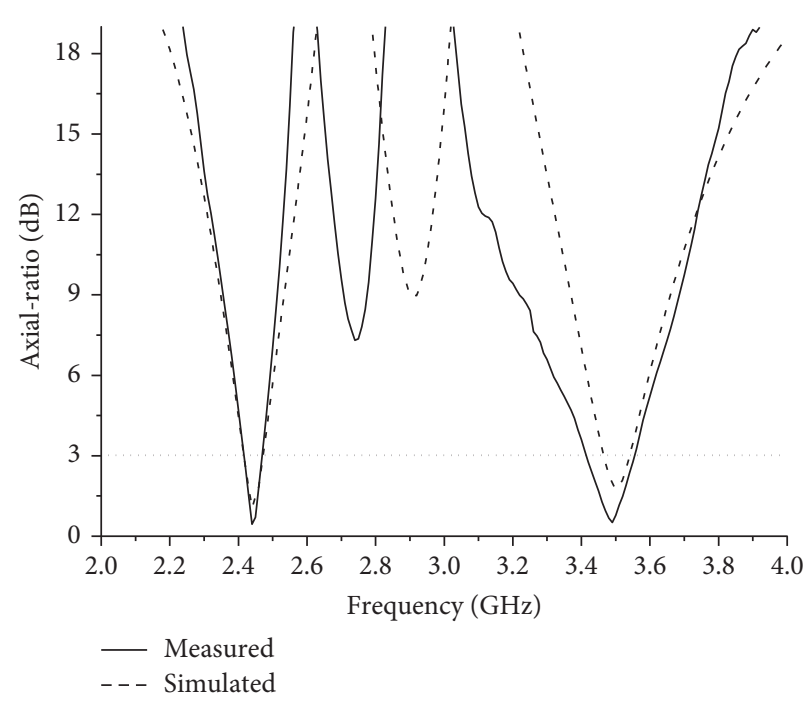

FIgURE 10: Simulated and measured axial-ratio of antenna.

the dual-band characteristic of the antenna. The antenna gain at $2.45 \mathrm{GHz}$ and $3.5 \mathrm{GHz}$ are $7.3 \mathrm{dBc}$ and $6 \mathrm{dBc}$, respectively. The measured efficiency of the antenna is shown in 


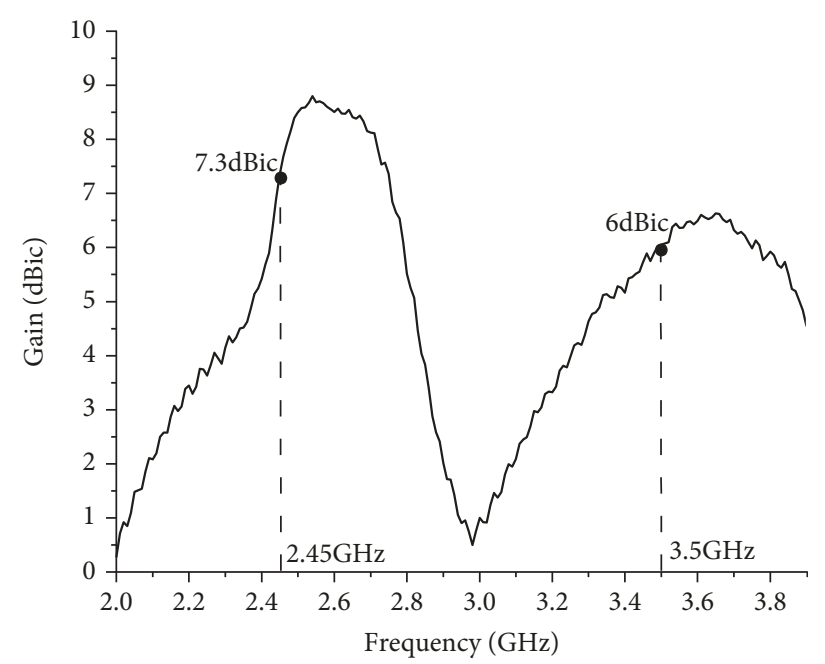

(a)

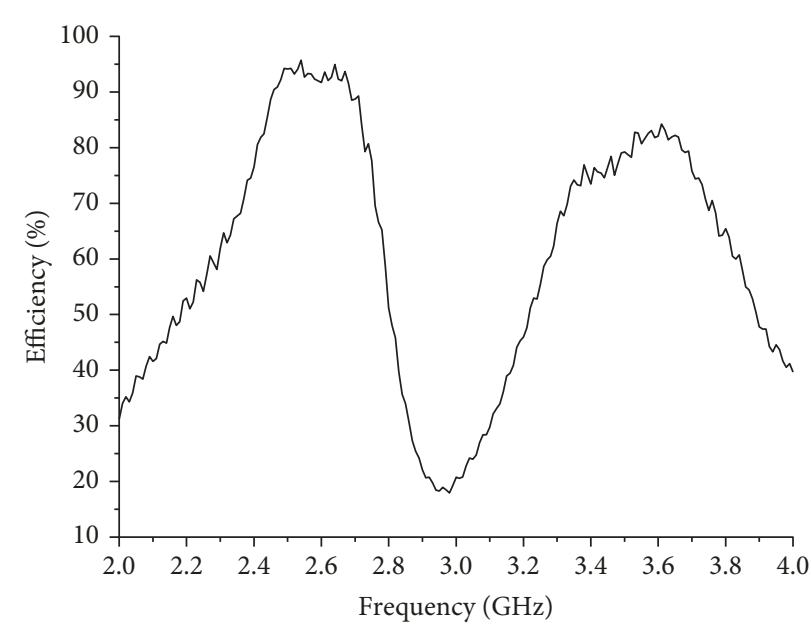

(b)

FIgURE 11: (a) Measured gain and (b) efficiency of the antenna.

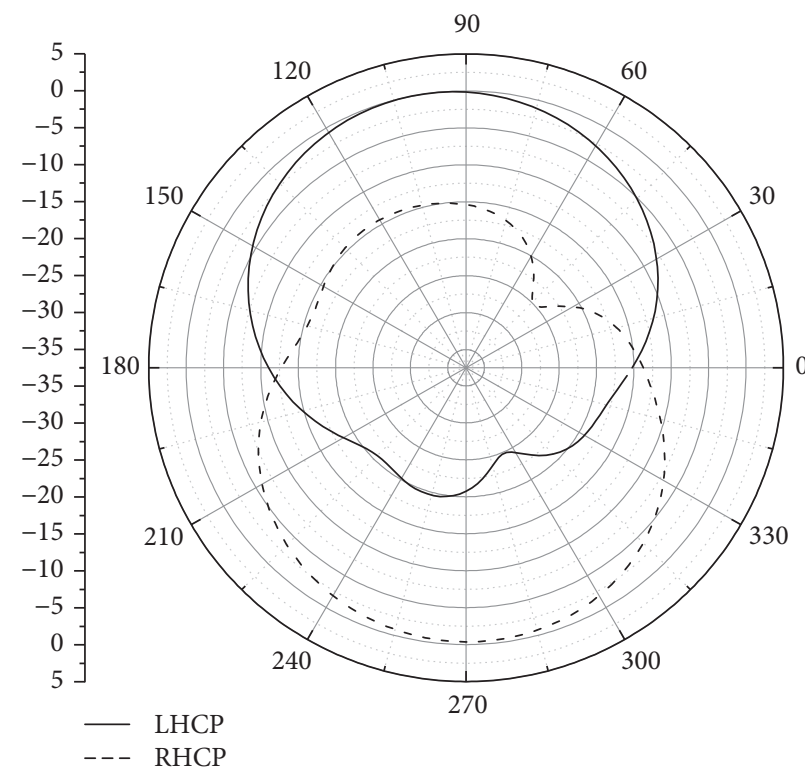

(a)

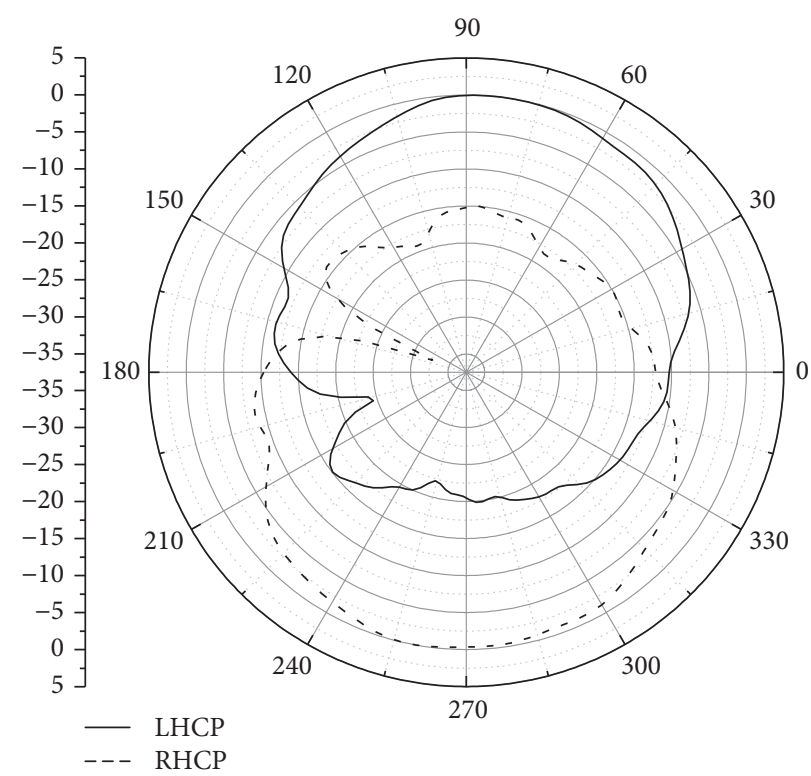

(b)

FIGURE 12: Measured radiation pattern at $2.45 \mathrm{GHz}$ : (a) XOZ plane; (b) YOZ plane.

Figure 11(b). The antenna efficiency of the lower frequency band is generally higher than $80 \%$ and reaches $88.7 \%$ at $2.45 \mathrm{GHz}$. The higher frequency efficiency is generally higher than $75 \%$ and $79.2 \%$ at $3.5 \mathrm{GHz}$.

Figures 12 and 13 depict the measured radiation pattern at $2.45 \mathrm{GHz}$ and $3.5 \mathrm{GHz}$, respectively. It can be seen that in the two E-plane patterns of the antenna operating at $2.45 \mathrm{GHz}$, the gain of the LHCP in the positive direction of the $Z$-axis is larger than $14.9 \mathrm{~dB}$ (XOZ plane) and $15.2 \mathrm{~dB}$ (YOZ plane) compared to the RHCP. Although the measured result is slightly inferior to the simulated one, the antenna still exhibits LHCP radiation in the positive direction of the $Z$-axis. In the negative direction of the $Z$-axis, the RHCP gain of the antenna is greater than the LHCP by $20.4 \mathrm{~dB}$ (XOZ plane) and $22 \mathrm{~dB}$ (YOZ plane), respectively, and the antenna radiates RHCP wave. The situation is the same as described above when the antenna is operating at $3.5 \mathrm{GHz}$. As can be seen from the radiation pattern, the antenna satisfies $\mathrm{CP}$-operating characteristics at both frequencies and exhibits LHCP radiation in the positive direction of the $Z$-axis, and the radiation patterns in the negative direction of the $Z$-axis are RHCP.

Finally, the proposed antenna is compared with other previously reported dual-band circularly polarized microstrip slot antennas in terms of gain, impedance matching bandwidth, and AR bandwidth, as tabulated in Table 2. In [9], the circular patch of the antenna is slotted with four complementary spiral slots for dual-band radiation. In [10], 


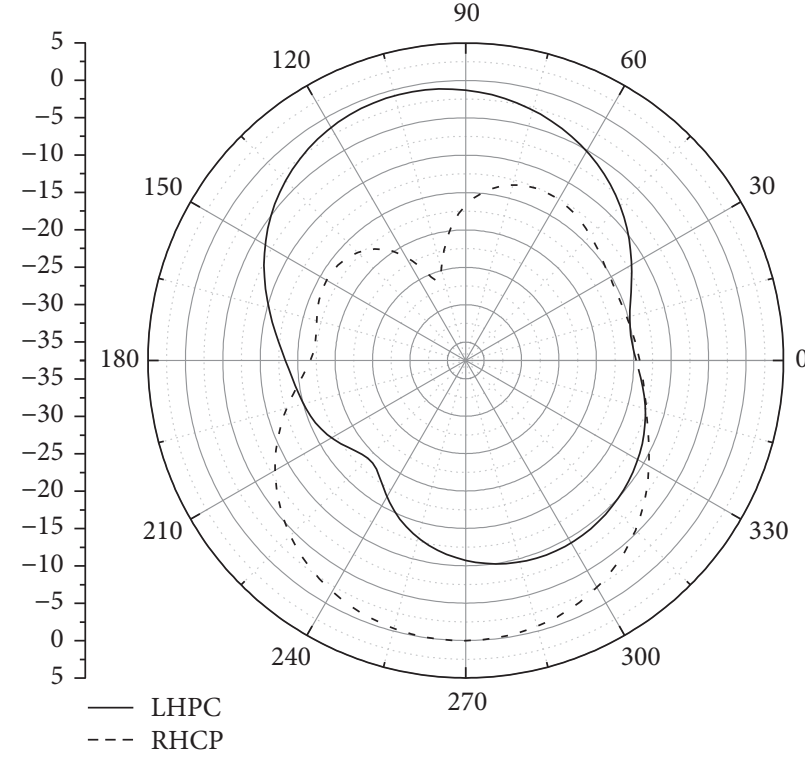

(a)

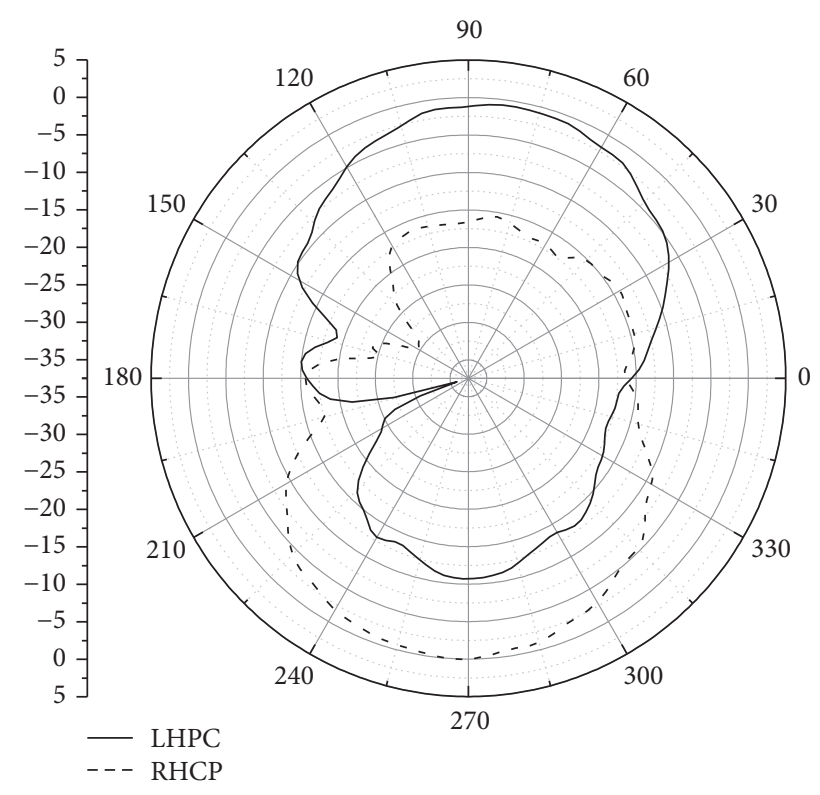

(b)

FIgURE 13: Measured radiation pattern at $3.5 \mathrm{GHz}$ : (a) XOZ plane; (b) YOZ plane.

TABLE 2: Comparisons between the proposed antenna and other dual-band circularly polarized microstrip slot antennas.

\begin{tabular}{lccccc}
\hline References & Overall size $(\mathrm{mm})$ & Impedance matching bandwidth & AR bandwidth & Gain (dBic) & Radiation efficiency \\
\hline$[9]$ & $50 \times 50 \times 1.6$ & $2.7 \% / 1 \%$ & $9.6 \% / 4 \%$ & $-1.9 /-6.9$ & - \\
{$[10]$} & $80 \times 80 \times 1.52$ & $26.7 \% / 11.3 \%$ & $6.1 \% / 6.0 \%$ & $5.2 / 6.3$ & - \\
{$[11]$} & $70 \times 70 \times 1.6$ & $106 \%$ & $32 \% / 5.6 \%$ & $3.81 / 3.44$ & - \\
{$[12,13]$} & $62 \times 60 \times 0.8$ & $8.6 \% / 15.5 \%$ & $15.7 \% / 15.5 \%$ & $4.3 / 3.0$ & - \\
{$[14]$} & $70 \times 70 \times 3$ & $25.8 \% / 47 \%$ & $4.3 \% / 3.6 \%$ & $3.3 / 4.5$ & - \\
This work & $\mathbf{6 0} \times \mathbf{6 0} \times \mathbf{1 . 6}$ & $\mathbf{1 4 \% / \mathbf { 1 0 } \%}$ & $\mathbf{1 . 2 3} \% / \mathbf{1 . 1 5 \%}$ & $\mathbf{7 . 3 / 6}$ & $\mathbf{8 8 . 7 \% / 7 9 . 2 \%}$ \\
\hline
\end{tabular}

a dual circularly polarized antenna augmented by four unequal linear slots is proposed. In [11], a coplanar waveguide- (CPW-) fed slot antenna with a C-shaped grounded strip is proposed for dual-sense circularly polarized radiation. In [12, 13], circular-shaped and hexagonal-shaped slot antenna using L-shaped stub along with microstrip feed line are studied and have the characteristics of bidirectional radiation. A square-ring slot antenna in [14], using symmetric perturbations structure, is designed for dual-sense CP radiation.

In comparison to the designs [9-14], the proposed antenna possesses small size, high gain, and high efficiency in dual band.

\section{Conclusion}

A dual-band CP microstrip antenna with a very simple structure is proposed in this paper. We can get the lower and upper operating frequency bands which we need by changing the dimensions of the annual ring slots. CP radiation pattern can be achieved by two folded perturbation structures at the diagonally $45^{\circ}$ diagonal position of each annular-ring slot, respectively. The antenna is designed, fabricated, and measured, and the measured results of the annular-ring microstrip antenna show good performance of a dual-band $\mathrm{CP}$ operation. The measured impedance bandwidths for both bands are above $350 \mathrm{MHz}$, and the bandwidth of axial ratio (AR) less than $-3 \mathrm{~dB}$ is about $30 \mathrm{MHz}$ for lower and upper frequency bands. The gain of the antenna in both of the two bands is larger than $6 \mathrm{dBic}$.

\section{Data Availability}

The data used to support the findings of this study are included within the article.

\section{Conflicts of Interest}

The authors declare that they have no conflicts of interest.

\section{Acknowledgments}

This work was supported in part by the National Natural Science Foundation of China under Grant no. 61471204 and the National and Local Joint Engineering Laboratory of RF Integration and Micro-Assembly Technology under Grant no. KFJJ20170206. 


\section{References}

[1] B. Li, Y. Du, B. Wang, Y. Kong, and X. Ye, "A design of dualband circularly polarized microstrip antenna with single feed on one single layer substrate," in 2017 International Applied Computational Electromagnetics Society Symposium (ACES), pp. 1-2, Suzhou, China, August 2017.

[2] Y.-M. Cai, K. Li, Y.-Z. Yin, and X. Ren, "Dual-band circularly polarized antenna combining slot and microstrip modes for GPS with HIS ground plane," IEEE Antennas and Wireless Propagation Letters, vol. 14, pp. 1129-1132, 2015.

[3] M. Fartookzadeh and S. H. Mohseni Armaki, "Enhancement of dual-band reflection-mode circular polarizers using duallayer rectangular frequency selective surfaces," IEEE Transactions on Antennas and Propagation, vol. 64, no. 10, pp. 4570-4574, 2016.

[4] S.-L. Ma and J.-S. Row, "Design of single-feed dual-frequency patch antenna for GPS and WLAN applications," IEEE Transactions on Antennas and Propagation, vol. 59, no. 9, pp. 34333436, 2011.

[5] C. Jin, R. Li, and X.-Y. Bao, "Circular polarization patch antenna design with diagonal periodic metallic via holes," Microwave and Optical Technology Letters, vol. 55, no. 5, pp. 1097-1100, 2013.

[6] K. Y. Lam, K. M. Luk, K. F. Lee, H. Wong, and K. B. Ng, "Small circularly polarized U-slot wideband patch antenna," IEEE Antennas and Wireless Propagation Letters, vol. 10, pp. 8790, 2011.

[7] Y.-J. Hu, W.-P. Ding, W.-M. Ni, and K. Wu, "Broadband circularly polarized microstrip-fed circular slot antenna array," in 2012 International Conference on Microwave and Millimeter Wave Technology (ICMMT), pp. 1-5, Shenzhen, China, 2012.

[8] Y.-Q. Zhang, X. Li, L. Yang, and S.-X. Gong, "Dual-band circularly polarized annular-ring microstrip antenna for GNSS applications," IEEE Antennas and Wireless Propagation Letters, vol. 12, pp. 615-618, 2013.

[9] L. Yang, L. J. Xu, Y. M. Bo, and M. Zhang, “A single-feed dualband circularly polarized microstrip antenna with spiral slots," in 2017 International Applied Computational Electromagnetics Society Symposium (ACES), pp. 1-2, Suzhou, China, August 2017.

[10] X. Bao and M. J. Ammann, "Dual-frequency dual-sense circularly polarized slot antenna fed by microstrip line," IEEE Transactions on Antennas and Propagation, vol. 56, no. 3, pp. 645-649, 2008.

[11] Y.-Y. Chen, Y.-C. Jiao, G. Zhao, F. Zhang, Z.-L. Liao, and Y. Tian, "Dual-band dual-sense circularly polarized slot antenna with a C-shaped grounded strip," IEEE Antennas and Wireless Propagation Letters, vol. 10, no. 10, pp. 915918, 2011.

[12] Nasimuddin, A. Alpones, and N. Jeevanandham, "Circularly polarized slot antennas with wideband performance," in 2015 Asia-Pacific Microwave Conference (APMC), pp. 1-3, Nanjing, China, December 2015.

[13] N. Jeevanandham, Nasimuddin, K. Agarwal, and A. Alphones, "Dual-band circularly polarized hexagonal-slot antenna," in 2012 42nd European Microwave Conference, pp. 834-837, Amsterdam, Netherlands, 2012.

[14] S.-W. Zhou, P.-H. Li, and Y. Wang, "A dual-band dual-sense circularly polarized square-ring slot antenna," in 2012 International Conference on Microwave and Millimeter Wave Technology (ICMMT), pp. 1-4, Shenzhen, China, May 2012. 


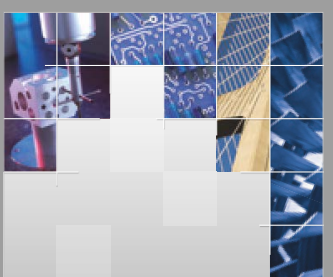

\section{Enfincering}
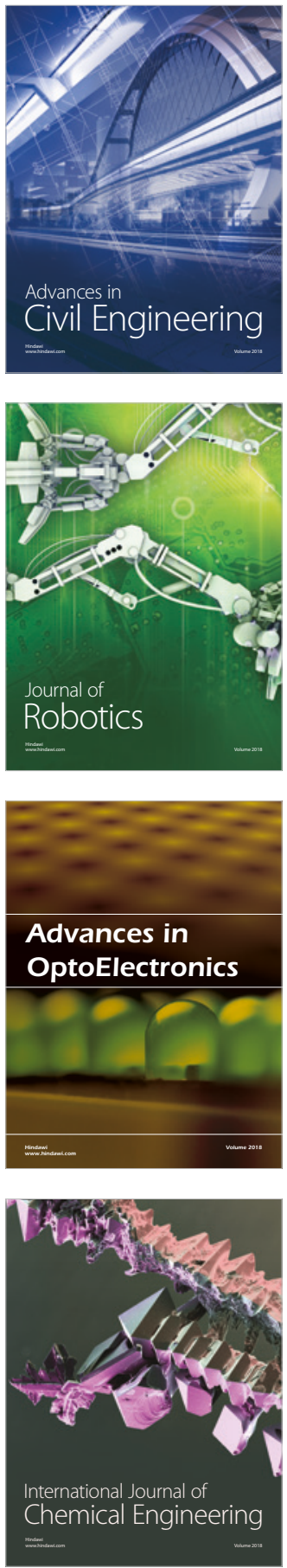

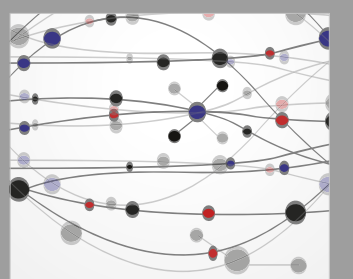

\section{Rotating \\ Machinery}

The Scientific World Journal

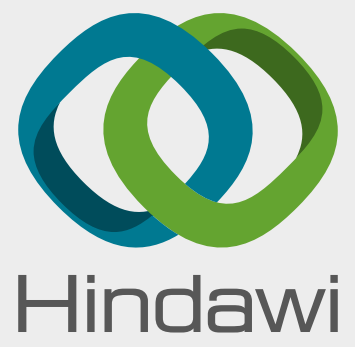

Submit your manuscripts at

www.hindawi.com
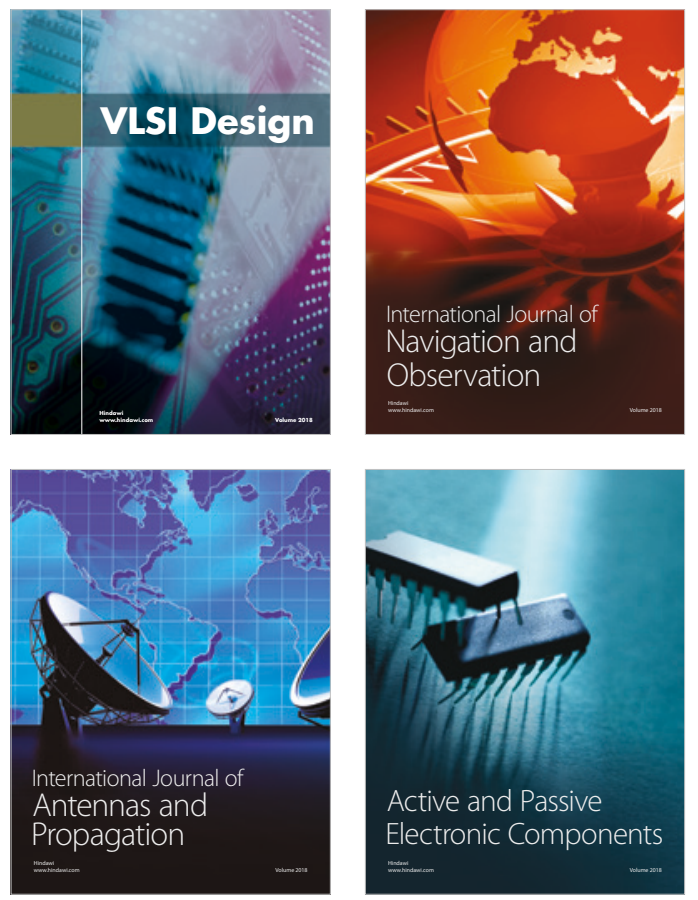
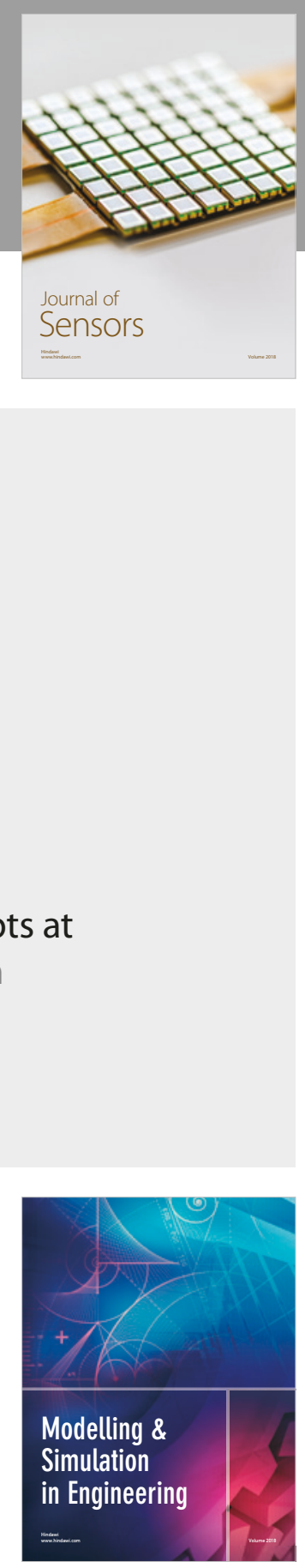

\section{Advances \\ Multimedia}
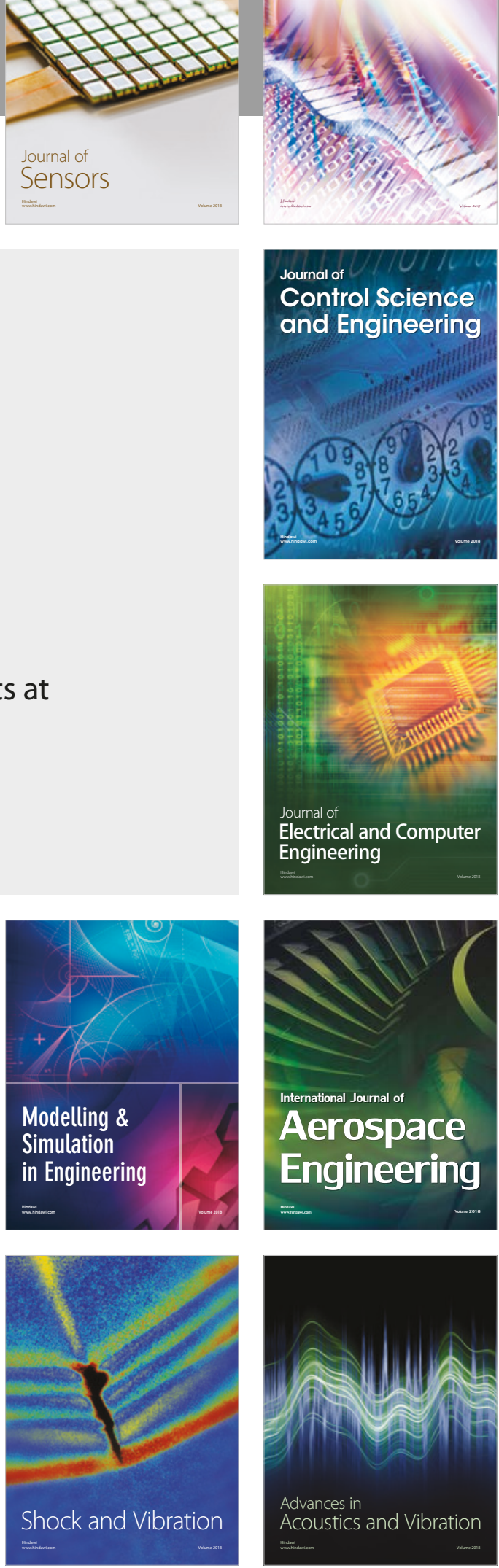